\title{
Current Knowledge on the Use of Letrozole in Ovarian Stimulation
}

\author{
Suchika Mangal
}

\begin{abstract}
Androgens are converted to estrogens by the enzyme called aromatase. This process called aromatization is inhibited by a group of drugs called aromatase inhibitors (Als). Letrozole is a nonsteroidal inhibitor that reversibly binds aromatase. Decrease in circulating estradiol level leads to release of negative feedback at hypothalamus pituitary level, thereby increasing follicle stimulating hormone (FSH) secretion resulting in stimulation of growth of ovarian follicles. Letrozole is well tolerated and is used in different protocols of ovarian stimulation. The extended spectrum of uses includes addition with gonadotrophins in poor responders, ovarian hyperstimulation syndrome (OHSS) prevention, fertility preservation in cancer patients. Due to its wide range of use, easy availability, affordability and good tolerability, Letrozole has emerged as a first line drug for ovulation induction.

Keywords: Aromatase inhibitor, Letrozole, Ovulation induction, Protocols.

International Journal of Infertility and Fetal Medicine (2020): 10.5005/jp-journals-10016-1205
\end{abstract}

\section{INTRODUCTION}

Estrogen is the steroid hormone indispensable for normal female physiology and reproduction. Estrogens are mainly produced in the ovary in a woman of reproductive age. Also, a small part of estrogen is released from the placental syncytiotrophoblasts, adipose tissue, brain, and skin fibroblasts. ${ }^{1}$ The three naturally produced estrogens in women's body are estrone, estradiol, and estriol. Out of these, estradiol is the main form of estrogen in women in the reproductive age group. Aromatase enzyme has a crucial role during estrogen synthesis from androgens. ${ }^{2}$ The human aromatase enzyme is a member of the cytochrome P450 family and is expressed by the CYP19A1 gene located on chromosome 15q21.2.,

Androstenedione and testosterone are converted to estrogens by the enzyme aromatase. This process is called aromatization and is inhibited by aromatase inhibitors (Als). As in the ovary, aromatase enzyme is available in different tissues, such as, adipose tissue, brain, liver, muscle, skin, bone, uterus, and breast tissue. In the late 1970s, Al was recognized as an agent with potential for use in hormonedependent breast cancer as an alternative to adrenalectomy. ${ }^{5}$

\section{Letrozole: Chemical Structure}

It is chemically described as 4,4'-(1H-1,2,4-Triazol-1-ylmethylene) dibenzonitrile. Letrozole is a light yellowish crystalline powder, odorless, slightly soluble in ethanol, and insoluble in water. Its molecular weight is 285.31 , the empirical formula is $\mathrm{C} 17 \mathrm{H} 11 \mathrm{~N} 5$, and a melting point range of 184 to $185^{\circ} \mathrm{C}$. Letrozole is available as 2.5 mg tablets for oral administration. ${ }^{6}$

The structural formula of letrozole is given in Figure 1.

\section{Generations of Aromatase Inhibitors}

Three generations of Als have been developed. The first-generation (aminoglutethimide) and second-generation Als (e.g., fadrozole and vorozole) were less selective and decreased aldosterone and cortisol production as well in addition to aromatase. Both were poorly tolerated and had limited clinical efficacy. ${ }^{7}$ Third-generation Als were later developed which were found to be highly selective for
Department of Reproductive Medicine, Milann: The Fertility Centre, Bengaluru, Karnataka, India

Corresponding Author: Suchika Mangal, Department of Reproductive Medicine, Milann: The Fertility Centre, Bengaluru, Karnataka, India, Phone: +91 9672404264, e-mail: suchika14@yahoo.in

How to cite this article: Mangal S. Current Knowledge on the Use of Letrozole in Ovarian Stimulation. Int J Infertil Fetal Med 2020;11(2): 48-53.

Source of support: Nil

Conflict of interest: None

the enzyme aromatase and are fairly well tolerated. Currently, three third-generation Als are approved for use in the United States. Both anastrozole and letrozole are non-steroidal inhibitors that reversibly bind aromatase. Exemestane is a steroidal Al that irreversibly binds the aromatase enzyme. All Als reduce systemic estrogen levels by as much as $98 \%{ }^{8}$ (Table 1).

\section{Mechanism of Action}

Various mechanisms of action of letrozole for use in ovarian stimulation have been described.

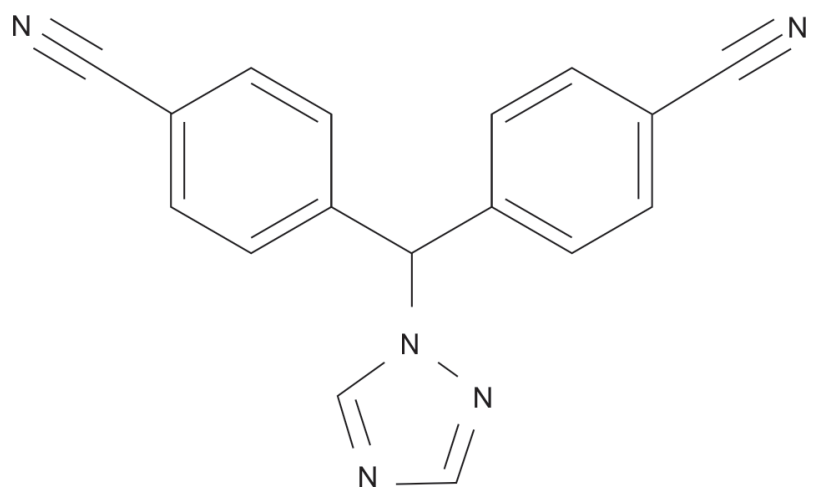

Fig. 1: Chemical structure of letrozole

(0) Jaypee Brothers Medical Publishers. 2020 Open Access This article is distributed under the terms of the Creative Commons Attribution 4.0 International License (https://creativecommons.org/licenses/by-nc/4.0/), which permits unrestricted use, distribution, and non-commercial reproduction in any medium, provided you give appropriate credit to the original author(s) and the source, provide a link to the Creative Commons license, and indicate if changes were made. The Creative Commons Public Domain Dedication waiver (http://creativecommons.org/publicdomain/zero/1.0/) applies to the data made available in this article, unless otherwise stated. 
Table 1: Generations of aromatase inhibitors

\begin{tabular}{lll}
\hline & Nonsteroidal & Steroidal \\
\hline First generation & Aminoglutethimide & \\
Second generation & Fadrozole & Formestane \\
Third generation & Letrozole, anastrozole & Exemestane \\
\hline
\end{tabular}

- Reduction of circulating estradiol levels leading to release of inhibition of the hypothalamic-pituitary axis from estrogenic negative feedback, therefore follicle stimulating hormone (FSH) secretion is increased, resulting in stimulating effect on the growth of ovarian follicles. ${ }^{9}$

- Aromatase inhibitors do not antagonize estrogen receptors in the brain and, therefore, the central feedback mechanism remains intact. The initiation of follicle growth accompanied by increasing concentrations of estrogens results in a normal negative feedback loop that limits FSH response and atresia of small follicles, generally leading to mono-ovulation.

- Peripheral mechanism of action: There is an increase of intraovarian androgen levels secondary to aromatase inhibition. This transient androgenic environment augments follicular sensitivity to FSH. The concept of androgens enhancing early follicular growth is becoming increasingly important. ${ }^{10}$

Recent data show that there is a role of androgens in early follicular developments by directly augmenting FSH receptors and indirectly by stimulating insulin-like growth factor (IGF)-l; FSH and IGF-I act synergistically to promote follicular growth. ${ }^{11-13}$

\section{Pharmacokinetics and Pharmacodynamics}

Following the oral administration of a single dose of letrozole $2.5 \mathrm{mg}$ in tablet form to healthy subjects, the drug is completely and rapidly absorbed from the gastrointestinal tract, reaching maximum plasma concentrations about 1 hour after single dosing. Absorption is not significantly affected by food. Letrozole is rapidly and extensively distributed into peripheral tissues. A daily dose of $2.5 \mathrm{mg}$ achieves an apparent stable distribution volume of $1.9 \mathrm{~L} /$ $\mathrm{kg}$. In plasma, $60 \%$ of letrozole is weakly bound to proteins, mostly albumin. The major route of elimination is hepatic metabolism to a pharmacologically inactive carbinol metabolite. The drug is excreted mainly through the kidneys. After administration of 2.5 mg, 14C-radiolabeled letrozole, $90 \%$ of radiolabeled letrozole is recovered in urine and only $4 \%$ in feces. Of letrozole recovered in urine, $65 \%$ corresponds to the glucuronide conjugate of carbinol, $9 \%$ to two unidentified metabolites, and $5 \%$ to unchanged letrozole. The terminal elimination half-life of letrozole is around 45 hours and steady-state plasma concentration after daily once $2.5 \mathrm{mg}$ dose is reached in 2-6 weeks. There is no change of pharmacokinetic parameters according to age. In patients with renal insufficiency or patients with mild to moderate liver dysfunction, dose adjustment of letrozole is not required. Side effects from letrozole are uncommon and related to estrogen insufficiency. ${ }^{14}$

\section{Indications for Aromatase Inhibitors in the Induction of Ovulation}

Aromatase inhibitors could be used alone for the induction of ovulation or as an adjuvant in conjunction with exogenous gonadotrophins to improve the outcome of ovulation induction. A major advantage of an Al when used alone is the ability to achieve mono-follicular ovulation in anovulatory infertility, especially women with a polycystic ovarian disease as a result of the intact estrogen negative feedback loop. Aromatase inhibitors could also be used with gonadotrophin injections to increase the number of follicles that develop in already ovulating women or controlled ovarian stimulation for in vitro fertilization (IVF). To summarize, Als when used alone should result in a predictable response with the development of one or two mature follicles and a significantly reduced risk for ovarian hyperstimulation syndrome (OHSS) and multiple gestations. To achieve multiple ovulation, the addition of gonadotrophins to Als is necessary. ${ }^{10}$

\section{Optimal Dose of Als for Repeated Administration}

The optimal or ideal dose of each Al is not yet clear. In most of the studies done to date, the dose of letrozole $(2.5 \mathrm{mg})$ or anastrozole $(1.0 \mathrm{mg})$ used for the treatment of postmenopausal women with breast cancer has been used and studied for ovulation induction as well. Biljan et al. in a randomized study compared letrozole 2.5 and $5.0 \mathrm{mg}$ in women with unexplained infertility and suggested that with a higher dose we might end up getting more follicles. However, the sample size was not large enough to attain the desired significance. ${ }^{15}$ Healey et al. used a dose of $5.0 \mathrm{mg}$ of letrozole along with FSH in an overlapping fashion for superovulation in women undergoing intrauterine insemination (IUI). ${ }^{16}$ Based on the current knowledge, it can be deduced that the optimal dose of letrozole for a 5-day course of treatment is between 2.5 and $5.0 \mathrm{mg}$, with higher doses resulting in longer aromatase inhibition and also causes lower estrogen levels, insufficient for normal endometrial development required around the time of ovulation. Although cumulative pregnancy rate (CPR) was considerably higher in patients resistant to clomiphene, the pregnancy rate was not significantly different between the $2.5,5$, and $7.5 \mathrm{mg}$ groups. Few complications like multiple pregnancies, irregular bleeding, and ovarian cyst, however, were higher with increased dosage. ${ }^{17}$

\section{Different Regimens of Letrozole}

The currently recommended dosage is $2.5-5 \mathrm{mg} /$ day for 5 days from day 3-7 of the periods, ${ }^{18-20}$ or as a single higher dose of 20 mg on day 3 of the periods. ${ }^{21}$ An extended regimen for 10 days has also been evaluated. ${ }^{22}$ The monitoring usually starts on day 7-8 of menses. In a review, letrozole could give an ovulation rate of $70-84 \%$ and a pregnancy rate of $20-27 \%$ per cycle in polycystic ovarian syndrome (PCOS) women resistant to clomiphene citrate. ${ }^{23}$ There were more follicles noted and a higher clinical pregnancy rate was reported in the longer regimen in which letrozole was given in a dose of $2.5 \mathrm{mg}$ daily for 10 days when compared with the standard regimen in which letrozole was given $5 \mathrm{mg}$ daily for 5 days. ${ }^{22}$ Another study comparing letrozole $2.5 \mathrm{mg}$ /day from cycle day 1-9 (211 cycles) to clomiphene citrate $100 \mathrm{mg} /$ day from day $3-7$ ( 210 cycles) in women undergoing IUI, concluded that there was no significant difference between the number of mature follicles. Serum estradiol levels were significantly higher in the clomiphene citrate group but the endometrial thickness was significantly greater in the extended letrozole group. Conception rate per cycle and CPR were significantly greater in the extended letrozole group (18.96 vs $11.43 \%$ and 37.73 vs $22.86 \%$, respectively). ${ }^{24}$

A relatively newer step-up protocol consisting of one, two, three, and four tablets of letrozole $(2.5 \mathrm{mg})$ daily on menstrual cycle days 2, 3, 4, and 5, respectively, is now well used and evaluated. In contrast to the monofollicular development associated with single and multiple fixed-dose regimens, the step-up letrozole protocol was associated with multifollicular development. To prevent 
rising estrogen from suppressing the FSH present endogenously, and thereby to extend the window of elevated endogenous gonadotropins, more aromatase inhibition is needed, which is accomplished by increasing the dose of the Als. ${ }^{25}$

Later, the use of letrozole was extended by the addition of gonadotrophins. A better number of follicles and improved endometrial thickness resulted in higher pregnancy rates in letrozole-HMG protocol group when compared to the letrozole alone group in unexplained infertility. ${ }^{26}$ Another study reported the concomitant use of letrozole with gonadotropins for ovarian stimulation in normal responders and concluded that the IVF cycles of patients treated with letrozole resulted in more mature oocytes and more blastocysts without any increased risk of OHSS reported. ${ }^{27}$

Recently, many studies have demonstrated the potential benefit of letrozole use in IVF cycles especially in women with breast cancer going through IVF for fertility preservation. ${ }^{28-31}$

\section{Comparison of Letrozole to Other Aromatase Inhibitors and with Clomiphene Citrate}

Other Als have also been compared with letrozole. In a prospective study, 22 PCOS women were assigned to letrozole $(2.5 \mathrm{mg} /$ day for 5 days) and 18 to anastrozole ( $1 \mathrm{mg} /$ day for 5 days). Letrozole was associated with a significantly higher ovulation rate ( 84.4 vs $60.0 \%)$ and pregnancy rate ( $27.0 \mathrm{vs} 16.6 \%)$ than anastrozole. ${ }^{32}$

As already described previously, in a review, letrozole gave an ovulation rate of $70-84 \%$ and a pregnancy rate of $20-27 \%$ per cycle in clomiphene-resistant PCOS women. ${ }^{23}$ Both single dose and split-dose regimens achieved similar clinical pregnancy rates. ${ }^{21}$ More follicles developed and higher clinical pregnancy rates were reported in the extended letrozole regimen ( $2.5 \mathrm{mg}$ daily for 10 days) when compared with the standard regimen (5 mg daily for 5 days). ${ }^{22}$

Comparison with other oral ovulogens: A meta-analysis of four prospective randomized studies ${ }^{20,33-35}$ revealed that the overall effects of letrozole when compared to clomiphene citrate were neither significant for ovulatory cycles (OR $=1.17 ; 95 \%$ ), nor for pregnancy rate per cycle $(\mathrm{OR}=1.47 ; 95 \%)$ or for pregnancy rate per patient $(\mathrm{OR}=1.37 ; 95 \%){ }^{9}$ In a Cochrane review on different ovarian stimulation protocols in IUI cycles, five studies comparing $\mathrm{CC}$ with letrozole found that there is no significant difference in the pregnancy rate (OR 1.2; 95\% Cl 0.64-2.1). ${ }^{36}$

In a recent randomized trial, comparing clomiphene and letrozole with gonadotrophins, endometrial thickness was found to be higher at the time of ovulation trigger in the letrozole group. Chemical and clinical pregnancy rates were much higher in the letrozole group. ${ }^{37}$

Al-Fozan et al. compared the effect of clomiphene and letrozole in women undergoing superovulation. No difference in pregnancy rates or endometrial thickness was found between the letrozole and the CC groups in this study. But miscarriage rate was interestingly found to be higher in the CC group. The reason is not very clear. ${ }^{38}$ Fatemi's research suggested less multiple gestations with letrozole, but more studies on larger numbers of multiple-gestation cases with letrozole are needed to confirm these findings. ${ }^{39}$ Other studies showed significantly lower estradiol levels in the letrozole group than in the clomiphene citrate group and more follicles developed in cycles stimulated with clomiphene citrate from the third to the seventh day of the cycle than in the letrozole group. The estrogen levels in women on Als were found to be $2-3$ times lower than those undergoing stimulation with CC; however, endometrial thickness was greater in the $\mathrm{Al}$ group. ${ }^{40,41}$

\section{Ban on Letrozole: A Serious Question Mark on Its Safety Profile}

The year 2005, saw a major setback to the use of wonder drug, letrozole for ovulation induction. Dr Marinko Biljan who hails from Montreal had presented an oral abstract at the American Society of Reproductive Medicine (ASRM) annual meeting held in 2005, reporting congenital anomalies in 150 babies born to infertile women offered letrozole for the induction of ovulation. ${ }^{42}$ There was a deep concern raised by this abstract submitted for the ASRM meeting though it was never published. Data from studies done later revealed that the alert of a higher risk of congenital cardiac and skeletal malformations in the newborns conceived after treatment with the letrozole, was never reproduced in any of the studies. ${ }^{43}$ Since then, many larger multicentric studies with better design have been published comparing the safety of letrozole and CC in the infertile group and also compared to the general population. It is postulated that as the half-life of letrozole is approximately 45 hours, it is cleared from the body completely by the time embryo implants, as compared to clomiphene citrate which remains in the body for a longer duration due to its longer half-life of 5-7 days. Letrozole is eliminated as an inactive carbinol metabolite mainly through the kidneys. Thus, the exposure to the drug predates the critical period of fetal development, casting doubt on the biological plausibility of teratogenicity with the use of letrozole for ovulation induction. Five years after the suspension of manufacture, sale, and distribution of the controversial drug letrozole, citing potential fetal side-effects, the Union Health Ministry's highest decision-making technical body on drugs has recommended lifting the ban and allowing the medicine to be used for administering in infertile women to help them conceive.

This move was followed by a recommendation by a scientific panel of the Indian Council for Medical Research (ICMR), which after conducting a detailed scientific study found that the benefits of the drug outweigh side-effects when used in infertile women.

Currently, two large randomized multicentric studies by the National Institute of Child Health and Human Development (NICHD) are ongoing, the results of which are awaited. These could provide definitive data for pregnancy outcomes with CC and letrozole.

One study, Pregnancy in Polycystic Ovary Syndrome-II (PPCOS-II), is a randomized controlled trial comparing CC with letrozole for ovulation induction in PCOS patients. ${ }^{44}$ They propose to enroll 750 women, across different centers. The primary outcome measure of the study would be the cumulative live birth rate (LBR).

Another study named Assessment of Multiple Intra Uterine Gestations from ovarian stimulation (AMIGOS) trial includes 240 women and aims to determine multiple pregnancy rates from OI and IUI and is a double-blinded study comparing CC or aromatase use. ${ }^{45}$ Cumulative and multiple pregnancy rates will be calculated. This trial is hoped to answer the issue of whether letrozole actually has a lower chance of multiple pregnancies, compared to clomiphene citrate or gonadotropins.

\section{Adverse Effects}

Letrozole is usually a very well-tolerated drug. Common side effects include hot flashes (11\%), nausea (7\%), fatigue (5\%), hair loss, and vaginal bleeding, which occur more frequently in breast cancer patients than in women treated for ovulation induction. This is due to differences in the duration of treatment. ${ }^{14}$

The multiple pregnancy rate is more as compared to natural conceptions. In a recent randomized controlled trial (RCT), ${ }^{46}$ on the 
pregnancy outcome after CC or letrozole treatment, the chance of twin pregnancies of letrozole was comparable to that of CC (8.3 vs 9.1\%). There was also a case report of a triplet pregnancy resulting from ovulation induction in a PCOS woman resistant to CC treatment. ${ }^{47}$ The teratogenic effects of letrozole are well described in animal studies. ${ }^{48,49}$ Letrozole is an FDA Category D drug and is contraindicated during pregnancy. ${ }^{6}$

\section{OHSS Prevention: A Newer Angle for the Use of Letrozole}

Letrozole is effective in reducing body weight, ovarian weight, vasoactive peptides, and vascular endothelial growth factor (VEGF) expression in OHSS and maybe a new treatment modality for preventing and controlling OHSS. ${ }^{50}$

In a study, a total of 88 patients were randomly divided into a control group not receiving letrozole, and groups treated with 2.5, 5, or $7.5 \mathrm{mg}$ of letrozole post oocyte retrieval. From the fifth day after human chorionic gonadotropin (HCG) trigger, the level of VEGF was found to increase in the control group, but decrease in the letrozole groups in a dose-dependent manner. The difference between the two groups was statistically significant $(p<0.001)$. The incidence of moderate and severe OHSS was lower in the $7.5 \mathrm{mg}$ group than in the control group $(p<0.05) .{ }^{51}$ Whether letrozole might reduce the risk of OHSS by reducing estrogen levels is controversial. $\mathrm{He}$ et al. demonstrated a decrease in the levels of VEGF which was dose-dependent, with increasing doses of letrozole administered in the luteal phase post oocyte retrieval. ${ }^{51}$ The findings suggest that letrozole could result in decreasing the risk of OHSS, although it is still doubtful if the effect on VEGF and PEDF secretion is a direct action of letrozole or an indirect effect due to reduction in estradiol levels.

Another randomized controlled study that aimed at comparing the efficacy of letrozole to aspirin for primary prevention of early OHSS showed that there was a lower incidence of OHSS in women receiving letrozole compared to aspirin. ${ }^{30}$ The lower incidence of OHSS was not correlated to lower levels of VEGF in blood. It was hypothesized by the authors that the mechanism might be independent of VEGF but may be due to the induction of a luteolytic effect and an estradiol decline which reduced the risk of early onset OHSS.

\section{Is There Any Effect of Letrozole on Endo Receptivity?}

Integrin expression, which is a marker of endometrial receptivity, is less in women with IVF failure. ${ }^{52}$ Miller et al. examined the effect of letrozole on integrin expression as a marker of endometrial receptivity. They found that a lack of endometrial integrin expression was associated with a poor prognosis for IVF because of poorer endometrial receptivity and that the results were improved with letrozole co-treatment. ${ }^{53}$

\section{Extension of Use of Letrozole for Women with Poor Ovarian Reserve: What is the Rationale?}

There have been newer studies on treating normoresponders with gonadotropins and letrozole during ovarian stimulation to improve response to FSH by increasing the intrafollicular androgen concentration and to reduce the circulating estrogen concentrations $^{27}$ (Table 2).

Because the dose of gonadotropins and the cost is significantly lower when letrozole is added, such an approach may be a realistic and cost-effective approach for women with poor ovarian reserve.
Table 2: Use of letrozole in poor responders

\begin{tabular}{|c|c|c|c|c|}
\hline Studies & $\begin{array}{l}\text { Stimulation } \\
\text { protocol }\end{array}$ & $\begin{array}{l}\text { Patients } \\
\text { (n) }\end{array}$ & $\begin{array}{l}\text { Clinical } \\
\text { pregnancy } \\
\text { rate }\end{array}$ & $\begin{array}{l}\text { No. of } \\
\text { oocytes }\end{array}$ \\
\hline Goswami et al. ${ }^{54}$ & $\begin{array}{l}\text { rFSH + letro- } \\
\text { zole + antag/ } \\
\text { rFSH + agonist }\end{array}$ & $13 / 25$ & $23 / 24$ & $1.6 / 2.1$ \\
\hline $\begin{array}{l}\text { Garcia-Velasco } \\
\text { et al. } .^{55}\end{array}$ & $\begin{array}{l}\text { rFSH + HMG } \\
+ \text { letrozole + } \\
\text { antag/rFSH + } \\
\text { HMG + antag }\end{array}$ & $71 / 76$ & $22.4 / 15.2$ & $6.1 / 4.3$ \\
\hline Ozmen et al. ${ }^{56}$ & $\begin{array}{l}\mathrm{rFSH}+ \\
\text { letrozole }+ \\
\text { antag/rFSH }+ \\
\text { antag }\end{array}$ & $35 / 35$ & $28.6 / 17.1$ & $4.9 / 4.8$ \\
\hline Davar et al. ${ }^{57}$ & $\begin{array}{l}\mathrm{rFSH} / \mathrm{HMG}+ \\
\text { letrozole + } \\
\text { antag/rFSH/ } \\
\text { HMG + agonist }\end{array}$ & $45 / 49$ & $3.8 / 7.7$ & $2.8 / 4.4$ \\
\hline Ersahin et al. ${ }^{58}$ & $\begin{array}{l}\text { rFSH }+ \\
\text { letrozole }+ \\
\text { antag/rFSH }+ \\
\text { antag }\end{array}$ & $30 / 30$ & $22 \% / 11 \%$ & $3.2 / 5.8$ \\
\hline
\end{tabular}

Nonetheless, the results need to be reproduced by large welldesigned trials.

\section{Conclusion}

Current evidence supports the use of Als as a safe solution for fertility preservation in cancer patients before chemotherapy. Letrozole plays a definitive role in women with clomiphene failure or resistance. Currently, available data comparing clomiphene and letrozole as first-line therapy for ovulation induction for women with anovulation is conflicting in nature and equivocal. For women with PCOS, letrozole has undoubtedly emerged as a wonder drug as it takes care of both clomiphene-resistant women and also for those who tend to have multifollicular response to clomiphene or gonadotrophins. Although letrozole may also have a role in the management of poor responder patients, results are based on few pieces of evidence and need to be reproduced in well-designed larger studies in the future, whereas its use in normoresponders requires even more intensive research for various indications. Its role in vitro fertilization (IVG) with gonadotrophins cannot be undermined. Also, newer indications warranting the use of letrozole for the prevention of life-threatening complication called OHSS are being increasingly accepted and welcomed.

\section{References}

1. Nelson LR, Bulun SE. Estrogen production and action. J Am Acad Dermatol 2001;45(3):116-124. DOI: 10.1067/mjd.2001.117432.

2. Gruber CJ, Tschugguel W, Schneeberger C, et al. Production and actions of estrogens. N Engl J Med 2002;346(5):340-352. DOI: 10.1056/ NEJMra000471.

3. Thompson EA, Siiteri PK. Utilization of oxygen and reduced nicotinamide adenine dinucleotide phosphate by human placental microsomes during aromatization of androstenedione. J Biol Chem 1974;249(17):5364-5372. DOI: 10.1016/S0021-9258(20)79735-8.

4. Chen S, Besman MJ, Sparkes RS, et al. Human aromatase: CDNA cloning, southern blot analysis, and assignment of the gene to chromosome 15. DNA 1988;7(1):27-38. DOI: 10.1089/dna.1988.7.27. 
5. Santen RJ, Brodie H, Simpson ER, et al. History of aromatase: saga of an important biological mediator and therapeutic target. Endocr Rev 2009;30(4):343-375. DOI: 10.1210/er.2008-0016.

6. Novartis, Femara (letrozole) tablets prescribing information. East Hanover, NJ.

7. Fabian CJ. The what, why and how of aromatase inhibitors: hormonal agents for treatment and prevention of breast cancer. Int J Clin Pract 2007;61(12):2051-2063. DOI: 10.1111/j.1742-1241.2007.01587.x.

8. Janicke F. Are all aromatase inhibitors the same? A review of the current evidence. Breast 2004;13(Suppl 1):S10-S18. DOI: 10.1016/j. breast.2004.09.003.

9. Requena A. Use of letrozole in assisted reproduction: a systematic review and meta-analysis. Hum Reprod Update 2008;14(6):571-582. DOI: 10.1093/humupd/dmn033.

10. Casper RF, Mohamed FM. Mitwally review: aromatase inhibitors for ovulation induction. J Clin Endocrinol Metabol 2006;91(3):760-771. DOI: $10.1210 /$ jc.2005-1923.

11. Kar S. Current evidence supporting "letrozole" for ovulation induction. J Hum Reprod Sci 2013;6(2):93-98. DOI: 10.4103/09741208.117166 .

12. Weil SJ, Vendola K, Zhou J, et al. Androgen receiptor gene expression in the primate ovary: cellular localization, regulation, and functional correlations. J Clin Endocrinol Metab 1998;837(7):2479-2485. DOI: 10.1210/jcem.83.7.4917.

13. Kamat A, Hinshelwood MM, Murry BA, et al. Mechanisms in tissuespecific regulation of estrogen biosynthesis in humans. Trends Endocrionol Metab 2002;133(3):122-128. DOI: 10.1016/S10432760(02)00567-2.

14. Bhatnagar AS, Häusler A, Schieweck K, et al. Highly selective inhibition of estrogen biosynthesis by CGS 20267, a new non-steroidal aromatase inhibitor. J Steroid Biochem Mol Biol 1990;37(6):1021-1027. DOI: 10.1016/0960-0760(90)90460-3.

15. Biljan MM, Tan SL, Tulandi T. Prospective randomized trial comparing the effects of 2.5 and $5.0 \mathrm{mg}$ of letrozole (LE) on follicular development, endometrial thickness and pregnancy rate in patients undergoing superovulation. Fertil Steril 2002;78:S55. DOI: 10.1016/ S0015-0282(02)03524-0.

16. Healey S, Tan SL, Tulandi T, et al. Effects of letrozole on superovulation with gonadotropins in women undergoing intrauterine insemination. Fertil Steril 2003;806(6):1325-1329. DOI: 10.1016/j. fertnstert.2003.03.001.

17. Rahmani E. Dosage optimization for letrozole treatment in clomiphene-resistant patients with Ppolycystic ovary syndrome: a prospective interventional study. Obstet Gynecol Int 2012;2012:758508.

18. Mitwally MFM, Casper RF. Aromatase inhibition: a novel method of ovulation induction in women with polycystic ovarian syndrome. Reprod Technol 2001;10:244-247.

19. Mitwally MF, Biljan MM, Casper RF. Pregnancy outcome after the use of an aromatase inhibitor for ovarian stimulation. Am J Obstet Gynecol 2005;192(2):381-386. DOI: 10.1016/j.ajog.2004.08.013.

20. Badawy A, Abdel Aal I, Abulatta M. Clomiphene citrate or letrozole for ovulation induction in women with polycystic ovarian syndrome: a prospective randomized trial. Fert Steril 2009;92(3):849-852. DOI: 10.1016/j.fertnstert.2007.02.062.

21. Mitwally MFM, Casper RF. Single dose administration of the aromatase inhibitor, letrozole: a simple and convenient effective method of ovulation induction. Fertil Steril 2001;76(3):S94-S95. DOI: 10.1016/ S0015-0282(01)02281-6.

22. Badawy A, Mosbah A, Tharwat A, et al. Extended letrozole therapy for ovulation induction in clomiphene-resistant women with polycystic ovary syndrome: a novel protocol. Fertil Steril 2009;92(1):236-239. DOI: 10.1016/j.fertnstert.2008.04.065.

23. Holzer $\mathrm{H}$, Casper R, Tulandi T. A new era in ovulation induction. Fertil Steril 2006;85(2):277-284. DOI: 10.1016/j.fertnstert.2005.05.078.

24. Fouda UM. Extended letrozole regimen versus clomiphene citrate for superovulation in patients with unexplained infertility undergoing intrauterine insemination: a randomized controlled trial. Reprod Biol Endocrinol 2011;9(1):84. DOI: 10.1186/1477-7827-9-84.

25. Mitwally MF, Said T, Galal A, et al. Letrozole step-up protocol: a successful superovulation protocol. Poster Presentat 2008;89(4):S23S24.

26. Malhotra N, Karmakar D, Kumar S. Letrozole alone or letrozole gonadotropin combination as first line for superovulation in women with unexplained infertility undergoing intrauterine insemination (IUI): a prospective randomized trial, fertility and sterility. 2012;98(3):S258.

27. Haas J, Bassil R, Meriano J, et al. Does daily co-administration of letrozole and gonadotropins during ovarian stimulation improve IVF outcome? Reprod Biol Endocrinol 2011;15(1):70. DOI: 10.1186/ s12958-017-0288-8.

28. Pereira N, Hancock K, Cordeiro CN, et al. Comparison of ovarian stimulation response in patients with breast cancer undergoing ovarian stimulation with letrozole and gonadotropins to patients undergoing ovarian stimulation with gonadotropins alone for elective cryopreservation of oocytes. Gynecol Endocrinol 2016;32(10):823-826. DOI: 10.1080/09513590.2016.1177013.

29. Quinn MM, Cakmak H, Letourneau JM, et al. Response to ovarian stimulation is not impacted by a breast cancer diagnosis. Hum Reprod 2017;32(3):568-574. DOI: 10.1093/humrep/dew355.

30. Mai Q, Hu X, Yang G, et al. Effect of letrozole on moderate and severe early-onset ovarian hyperstimulation syndrome in high-risk women: a prospective randomized trial. Am J Obstet Gynecol 2017;216(1):42. e1-42.e10. DOI: 10.1016/j.ajog.2016.08.018.

31. Goldrat O, Gervy C, Englert Y, et al. Progesterone levels in letrozole associated controlled ovarian stimulation for fertility preservation in breast cancer patients. Hum Reprod 2015;30(9):2184-2189. DOI: 10.1093/humrep/dev155.

32. Al-Omari WR, Sulaiman WR, Al-Hadithi N. Comparison of two aromatase inhibitors in women with clomiphene-resistant polycystic ovary syndrome. Int J Gynaecol Obstet 2004;85(3):289-291. DOI: 10.1016/j.ijgo.2003.11.010.

33. Atay V, Cam C, Muhcu M, et al. Comparison of letrozole and clomiphene citrate in women with polycystic ovaries undergoing ovarian stimulation. J Int Med Res 2006;34(1):73-76. DOI: 10.1177/147323000603400109.

34. Bayar Ü, Tanrıverdi HA, Barut A, et al. Letrozole vs clomiphene citrate in patients with ovulatory infertility. Fertil Steril 2006;85(4):1045-1048. DOI: 10.1016/j.fertnstert.2005.09.045.

35. Sohrabvand F, Ansari SH, Bagheri M. Efficacy of combined metformin letrozole in comparison with metformin clomiphene citrate in clomiphene-resistant infertile women with polycystic ovarian disease. Hum Reprod 2006;21(6):1432-1435. DOI: 10.1093/humrep/ del020.

36. Cantineau AE, Cohlen BJ, Heineman MJ. Ovarian stimulation protocols (antioestrogens, gonadotrophins with and without GnRH agonists/ antagonists) for intrauterine insemination (IUI) in women with subfertility. Cochrane Database Syst Rev 2007(2):CD005356.

37. Pourali L, Ayati S, Tavakolizadeh S, et al. Clomiphene citrate versus letrozole with gonadotropins in intrauterine insemination cycles: a prospective randomized trial. Int J Reproduct Biomedic 2017;15(1):4954.

38. Al-Fozan $\mathrm{H}, \mathrm{Al}-\mathrm{Khadouri} \mathrm{M}$, Tan $\mathrm{SL}$, et al. A randomized trial of letrozole versus clomiphene citrate in women undergoing superovulation. Fertil Steril 2004;82(6):1561-1563. DOI: 10.1016/j. fertnstert.2004.04.070.

39. Fatemi HM, Kolibianakis E, Tournaye $\mathrm{H}$, et al. Clomiphene citrate versus letrozole for ovarian stimulation: a pilot study. Reprod Biomed Online 2003;7(5):543-546. DOI: 10.1016/S1472-6483(10)62070-6.

40. Nasseri S, Ledger WL. Clomiphene citrate in the twenty-first century. Am Fam Physician 2000;62(5):1079-1088, 1090.

41. Homburg R. Polycystic ovary syndrome - induction of ovulation. Human Rreproduction 1996;11(1):29-39. DOI: 10.1093/oxfordjournals. humrep.a019031. 
42. Biljan MM, Hemmings R, Brassard N. The outcome of 150 babies following the treatment with letrozole or letrozole and gonadotropins. Fertil Steril 2005;84(Suppl 1):S95. DOI: 10.1016/j. fertnstert.2005.07.230.

43. Tulandi T, Martin J, Al-Fadhli R, et al. Congenital malformations among 911 newborns conceived after infertility treatment with letrozole or clomiphene citrate. Fertil Steril 2006;85(6):1761-1765. DOI: 10.1016/j. fertnstert.2006.03.014.

44. Legro RS, Kunselman AR, Brzyski RG, et al. The pregnancy in polycystic ovary syndrome II (PPCOS II) trial: rationale and design of a doubleblind randomized trial of clomiphene citrate and letrozole for the treatment of infertility in women with polycystic ovary syndrome. Contemp Clin Trials 2012;33(3):470-481. DOI: 10.1016/j.cct.2011.12.005.

45. Diamond MP, Mitwally M, Casper R, et al. Estimating rates of multiple gestation pregnancies: sample size calculation from the assessment of multiple intrauterine gestations from ovarian stimulation (AMIGOS) trial. Contemp Clin Trials 2011;32(6):902-908. DOI: 10.1016/j. cct.2011.07.009.

46. Badawy A, Shokeir T, Allam AF, et al. Pregnancy outcome after ovulation induction with aromatase inhibitors or clomiphene citrate in unexplained infertility. Acta Obstetricia et Gynecologica 2009;88(2):187-191. DOI: 10.1080/00016340802638199.

47. Dicken $\mathrm{CL}$, Nakhuda GS, Guarnaccia MM, et al. Triplet pregnancy after ovulation induction with an aromatase inhibitor. Fertil Steril 2008;90(4):1199.e9-11. DOI: 10.1016/j.fertnstert.2007.08.065.

48. Bishai R, Arbour L, Lyons C, et al. Intrauterine exposure to clomiphene and neonatal persistent hyperplastic primary vitreous. Teratology 1999;60(3):143-145. DOI: 10.1002/(SICI)10969926(199909)60:3<143::AID-TERA9>3.0.CO;2-\#.

49. Tiboni GM. Aromatase inhibitors and teratogenesis. Fertil Steril 2004;81(4):1158-1159. DOI: 10.1016/j.fertnstert.2004.01.006.

50. Akman L, Akdogan A, Erbas O, et al. Effect of letrozole for prevention of ovarian hyperstimulation syndrome (OHSS) in a rat model. Fertil Steril 2013;100(3):S258. DOI: 10.1016/j.fertnstert.2013. 07.1086 .

51. He Q, Liang L, Zhang C, et al. Effects of different doses of letrozole on the incidence of early-onset ovarian hyperstimulation syndrome after oocyte retrieval. Syst Biol Reprod Med 2014;60(6):355. DOI: 10.3109/19396368.2014.957879.

52. Thomas K, Thomson A, Wood S, et al. Endometrial integrin expression in women undergoing in vitro fertilization and the association with subsequent treatment outcome. Fertil Steril 2003;80(3):502-507. DOI: 10.1016/S0015-0282(03)00792-1.

53. Miller PB, Parnell BA, Bushnell G, et al. Endometrial receptivity defects during IVF cycles with and without letrozole. Hum Reprod 2012;27(3):881-888. DOI: 10.1093/humrep/der452.

54. Goswami SK, Das T, Chattopadhyay R, et al. A randomized singleblind controlled trial of letrozole as a low-cost IVF protocol in women with poor ovarian response: a preliminary report. Hum Reprod 2004;19(9):2031-2035. DOI: 10.1093/humrep/deh359.

55. Garcia-Velasco JA, Moreno L, Pacheco A, et al. The aromatase inhibitor letrozole increases the concentration of intraovarian androgens and improves in vitro fertilization outcome in low responder patients: a pilot study. Fertil Steril 2005;84(1):82-87. DOI: 10.1016/j. fertnstert.2005.01.117.

56. Ozmen B, Sönmezer M, Atabekoglu CS, et al. Use of aromatase inhibitors in poor-responder patients receiving $\mathrm{GnRH}$ antagonist protocols. Reprod Biomed Online 2009;19(4):478-485. DOI: 10.1016/j. rbmo.2009.05.007.

57. Davar R, Oskouian H, Ahmadi S, et al. GnRH antagonist/letrozole versus microdose $\mathrm{GnRH}$ agonist flare protocol in poor responders undergoing in vitro fertilization. Taiwan J Obstet Gynecol 2010;49(3):297-301. DOI: 10.1016/S1028-4559(10)60064-2.

58. Ersahin A, Gorgen B, Kahraman S. Letrozole in poor responders: a comparative study with previous cycles. Fertil Steril 2013;100(3):S508. DOI: 10.1016/j.fertnstert.2013.07.208. 